\title{
Comparison of a three-dimensional numerical model for fire resistance of axially loaded concrete filled steel tubular columns with Eurocode 4
}

\author{
Ana Espinós, Carmen Ibáñez, Manuel L. Romero*, Antonio Hospitaler \\ Instituto de Ciencia y Tecnología del Hormigón (ICITECH) \\ Universidad Politécnica de Valencia, Camino de Vera s/n, 46022 Valencia (Spain) \\ *mromero@mes.upv.es
}

\begin{abstract}
In this paper, the behaviour of slender axially loaded square and circular CFT columns exposed to fire is modelled using the finite element analysis package ABAQUS. A realistic sequentially coupled nonlinear thermal-stress analysis is conducted for a series of columns available in the literature. By means of this model, a comparison between fire resistance simulations results and experimental tests found in literature is made. Similarly, simulations results are compared to the Eurocode 4 simplified calculation model predictions. Comparisons show that whereas Eurocode 4 predictions are very conservative for both circular and square section CFT columns, the results obtained from the developed numerical model are much more realistic.
\end{abstract}

Keywords: Fire resistance; Concrete filled tubular column; Finite element analysis; Simple calculation model, Eurocode 4 


\section{INTRODUCTION}

Concrete filled tubular (CFT) columns are composite members that consist of a steel tube filled with concrete. Filling hollow steel columns with concrete is an interesting way to improve not only the bearing capacity of the columns but also their fire resistance [1]. Surface temperature of a hollow structural section without external protection increases quickly during the development of a fire. On the contrary, whether the steel tube is filled with concrete, while the steel section loses gradually its resistance and rigidity, the load is transferred to the concrete core, that heats up more slowly, thus increasing the fire resistance of the column.

In addition to its structural function, the steel tube acts as a radiation shield to the concrete core, what, combined with a steam layer in the steel-concrete boundary, leads to a lower temperature rise in the concrete core when compared to exposed reinforced concrete structures [1].

As a consequence of the different thermal conductivities of steel and concrete, the temperature distribution in the cross-section of a CFT column is not uniform during a fire. This fact generates a behaviour characterized by noticeable heating transients and high temperature differentials across the cross-section. Due to these differentials, CFT columns can reach high fire resistance times without external fire protection [1]. However, it is necessary to resort to numerical models in order to predict accurately these temperature profiles along the fire exposure time [2] [3].

In this work, the finite element analysis package ABAQUS [4] was employed to model the behaviour of slender axially loaded circular and square CFT columns exposed to fire. With this software, a sequentially coupled nonlinear thermal-stress analysis was conducted. The results of the simulations were compared with a series of fire resistance tests available in 
the literature [5] [6] [7], as well as with the predictions of the Eurocode 4 [8] simplified calculation model.

\section{DEVELOPMENT OF THE NUMERICAL MODEL}

\subsection{Finite element mesh of the model}

A three-dimensional numerical model was developed in ABAQUS [4], with variable parameters such as the length of the column $(L)$, the external size or diameter $(D)$, the thickness of the steel tube $(t)$, the presence of reinforcement and the thermal and mechanical material properties. It consisted of two or three parts: the concrete core, the steel tube and, according to the case, the reinforcement. Due to symmetry on the geometry and boundary conditions, only a quarter of the column was modelled.

The model was meshed with three-dimensional eight-node solid elements, for both the concrete core and the steel tube. In the case of reinforcing bars, two-node elements were used. The mesh density was controlled to have a maximum element size of $2 \mathrm{~cm}$, what, by means of a prior sensitivity analysis, was proved to be sufficient to predict with enough accuracy the thermal and mechanical behaviour of the CFT columns under fire. The finite element mesh for one of the CFT columns studied can be found in Fig. 1 .

\subsection{Material properties}

The numerical model took into account the temperature dependent thermal and mechanical properties of the materials. For modelling mechanical behaviour of concrete, Lie's model [9] was employed, provided that it proved to be the one that best predicted the behaviour of the concrete infill in CFT columns, as said by Hong \& Varma [3]. The mechanical model implemented in ABAQUS employed the hyperbolic Drucker-Prager yield surface. The thermal properties for concrete at elevated temperatures were extracted from EN 
1992-1-2 [10]. For steel, the temperature dependent thermal and mechanical properties recommended in EN 1993-1-2 [11];Error! No se encuentra el origen de la referencia. were adopted. The isotropic multiaxial plasticity model with the Von Mises yield surface was employed.

The constant values of the thermal expansion coefficient for concrete $\left(\alpha_{c}\right)$ and steel $\left(\alpha_{s}\right)$ recommended by Hong and Varma [3] were employed: $\alpha_{s}=12 \times 10^{-6}{ }^{\circ} \mathrm{C}^{-1}, \alpha_{c}=6 \times 10^{-6}{ }^{\circ} \mathrm{C}^{-1}$. With regard to the moisture content of the concrete infill, it is necessary to take into account that the lower the moisture content, the less the heat spent in evaporating the water and thus the more the heat dedicated to increase the column temperature. Therefore, columns with low moisture contents have an earlier failure than those with a great percentage of moisture, since they get much higher temperatures. In this research, the moisture content of the concrete infill was not modelled, what lies on the safe side.

\subsection{Thermal analysis}

For conducting the thermal analysis, the standard ISO-834 [12] fire curve was applied to the exposed surface of the CFT column model as a thermal load through the convection and radiation heat transfer mechanisms. The thermal contact in the steel-concrete boundary was modelled by employing the "gap conductance" and "gap radiation" options. The thermal resistance at the boundary between the steel tube and the concrete core was modelled by employing a constant value of $200 \mathrm{~W} / \mathrm{m}^{2} \mathrm{~K}$ for the gap conductance.

For the governing parameters of the heat transfer problem, the values recommended in EN 1991-1-2 [13] were adopted.

- Coefficient of convective heat transfer at the exposed surface: $\mathrm{h}=25 \mathrm{~W} / \mathrm{m}^{2} \mathrm{~K}$.

- Configuration factor for radiation at the exposed surface: $\Phi=1$.

- Stephan-Boltzmann constant: $\sigma=5.67 \times 10^{-8} \mathrm{~W} / \mathrm{m}^{2} \mathrm{~K}^{4}$. 
- Emissivity of the exposed surface: $\varepsilon=0.7$.

- Emissivity of the fire: $\varepsilon=1$.

- Initial temperature: $\mathrm{T}_{0}=20^{\circ} \mathrm{C}$

The three-dimensional eight-node heat transfer solid element with nodal temperature degree of freedom DC3D8 was used to mesh the thermal model. The reinforcing bars for the reinforced specimens were modelled using two-node heat transfer links DC1D2.

The nodal temperature-time curves resulting from the nonlinear heat transfer analysis were subsequently applied to the mechanical model as a thermal load.

\subsection{Mechanical analysis}

After the thermal analysis, a nonlinear stress analysis was carried out using also ABAQUS taking into account the nodal temperature-time curves previously calculated. The three-dimensional eight-node solid element C3D8RT was used to mesh the concrete core and the steel tube. These elements were thermally coupled bricks, with reduced integration and hourglass control. For modelling the longitudinal steel bars for the reinforced specimens, twonode T3D2 truss elements with both nodes tied to their corresponding concrete nodes were used.

In order to model the mechanical interaction between the steel tube and concrete infill contacting surfaces the next models were used. A "hard point" contact formulation was employed for the normal behaviour, which allows any pressure value when the surfaces are in contact and transmits no pressure when the surfaces do not contact. The tangent behaviour made use of the Coulomb friction model with a constant friction coefficient of 0.3. 


\section{VALIDATION OF THE NUMERICAL MODEL}

The three-dimensional numerical model was validated by comparing the simulations with experimental fire resistance tests [5] [6] [7] and with the EC4 simplified calculation model [8].

\subsection{Specimens tested}

\section{a) Circular columns}

The numerical model was employed to predict the standard fire behaviour of a series of circular section CFT column specimens listed in Table 1. These specimens were tested at the NRCC, and their results published by Lie \& Caron [5]. All the specimens tested were circular, filled with siliceous aggregate concrete and subjected to concentric compression load. Their total length was $3810 \mathrm{~mm}$, although only the central $3048 \mathrm{~mm}$ were directly exposed to fire. Because of the loading conditions, all the tests were assumed as fix-ended.

\section{b) Square columns}

Following the process explained above, the fire behaviour of eight square section CFT columns was studied by means of the numerical model developed. The characteristics of these specimens are shown in Table 2. Four of these columns were tested at the NRCC, and their results published by Lie \& Chabot [6], and the rest of the specimens were tested by Grandjean et al. [7];Error! No se encuentra el origen de la referencia. at CIDECT. In this series, all the columns tested were square, filled with reinforced concrete and subjected to concentric compression load. Only $3400 \mathrm{~mm}$ of the $3600 \mathrm{~mm}$ of their total length were directly exposed to fire. As in the previous series of circular columns, the ending conditions of all the columns were assumed as fixed. 


\subsection{Comparison with experimental results}

For each simulation, the axial displacement at the top of the column versus the fire exposure time was registered, comparing this curve with the one obtained in the fire resistance test [5] [6] [7] . Fig. 2 and Fig. 3 show an example of the comparison between both curves for a circular and a square specimen respectively.

From these curves, the fire resistance rating (FRR) was obtained for each one of the specimens under study. The failure criteria from EN 1363-1 [14] were adopted. This standard establishes that the failure time is given by the most restrictive from the following two limits:

- Maximum axial displacement: $C=\frac{h}{100} \mathrm{~mm}$

- Maximum axial displacement velocity: $\frac{d C}{d t}=\frac{3 h}{1000} \mathrm{~mm} / \mathrm{min}$

By applying these criteria, the values in Table 3 and Table 4 were obtained.

In case of circular section CFT, as it can be seen in Fig. 4, most of the values obtained lie in the region of the $15 \%$ error, apart from two values, corresponding to columns no. 1 and 2, which have the smallest diameters.

On the other hand, for square section CFT columns, the fire resistance rating (FRR) values are shown in Fig. 5 and again it can be seen that most of them are placed in the $\pm 15 \%$ region. There are only two values that lie outside these boundaries and they correspond to specimens no. 11 and 12, which have one of the biggest size of the series studied and are filled with concrete with a grade near $50 \mathrm{MPa}$ (48.1 and $47 \mathrm{MPa}$ respectively), what corresponds to high strength concrete.

The maximum axial displacement $\left(\delta_{\max }\right)$ was also obtained for each column studied. Table 3 and Table 4 show the calculated and measured values, which are plotted in Fig. 6 and Fig. 7. 
With regard to circular section CFT columns, it can be seen again that most of the cases lie in the region of the $15 \%$ error, apart from specimens no. 3 and 8 , corresponding to those with a higher loading level, over the $20 \%$ of the maximum load bearing capacity of the column at room temperature.

However, for square section CFT columns most of the cases are placed out of the $\pm 15 \%$ region, mainly in the safe side of the graph. Specimens no. 10 and 11 are those which lie more separately from the $15 \%$ error region, corresponding again with columns of big dimensions and filled with concrete of slightly higher grade than the rest. This fact shows that the numerical model is not able to predict with enough accuracy the maximum axial displacement produced in square section columns filled with reinforced concrete.

\subsection{Comparison with Eurocode 4 simplified calculation model}

In this section, the numerical model is compared with the predictions of the EC4 simplified calculation model [8], obtaining the results shown in Table 5 and Table 6. For both kinds of sections, circular and square, it can be seen in Fig. 8 and Fig. 9 that the proposed numerical model gives a better prediction of the fire resistance rating, showing a very accurate trend.

On the other hand, the EC4 simplified model turns out to be excessively conservative, as shown in the figure. We must note that the EC4 simplified model doesn't take into account the thermal expansion of the materials, nor the air gap at the steel-concrete boundary, what lies on the safe side and gives a very conservative prediction. If we apply these simplifications to our numerical model, smaller values of the fire resistance ratings are obtained, very similar to those predicted by EC4, as shown in Table 5 and Table 6. As it can be seen in Fig. 10 and Fig. 11, our predicted values reproduce quite well the results of EC4. 
Regarding to circular section CFT columns, values obtained applying the simplifications above to our numerical model reproduce with high accuracy the results of EC4, except for those tests with fire resistance ratings around 120 minutes, where our numerical model provides more accurate results, what produces a more close to reality trend.

In the case of square section specimens, the results of fire resistance time obtained by applying these simplifications to our numerical model are not as good as the ones corresponding to circular section columns. However, the values predicted by our model provide a more realistic behaviour than those obtained by applying the EC4 simplified calculation model.

\section{SUMMARY AND CONCLUSIONS}

A three-dimensional numerical model for axially loaded slender circular and square section CFT columns under fire was presented. By means of this model, the behaviour under standard fire conditions of sixteen column specimens previously tested by the NRCC research group [5] [6] and CIDECT [7];Error! No se encuentra el origen de la referencia., respectively, was predicted.

For circular section CFT columns, the proposed numerical model showed better behaviour for columns with low slenderness and loading levels under $20 \%$. Despite these two aspects, the model shows an accurate response when contrasted with the fire tests.

For square section CFT columns with reinforcement, the numerical model developed also provided more accurate values for specimens with low slenderness and filled with concrete of grades lower than $40 \mathrm{MPa}$.

This study also proved that the predictions of EC4 simplified calculation model [8] can be reproduced with the proposed numerical model by eliminating the thermal expansion of the materials, which lies on the safe side. Nevertheless, if the real behaviour of CFT columns 
under fire wants to be predicted, this aspect must be taken into account, extending the failure time. The expansion of the steel tube produces an opposed axial strain in the early stages of heating, as well as an opening of the gap in the steel-concrete interface, which delays the heating of the concrete core and thus increases the fire resistance rating.

The proposed numerical model proved to give better predictions than the EC4 simplified model, which turned out to be excessively conservative for both circular and square section specimens.

\section{ACKNOWLEDGEMENTS}

The authors express their sincere gratitude to the Spanish "Ministerio de Ciencia e Innovación" for the help provided through the Project BIA2009-9411 and to the European Union through the FEDER funds.

\section{REFERENCES}

[1] CIDECT. Twilt L, Hass R, Klingsch W, Edwards M, Dutta D. Design guide for structural hollow section columns exposed to fire. CIDECT (Comité International pour le Développement et l'Etude de la Construction Tubulaire). Cologne, Germany: Verlag TÜV Rheinland; 1996.

[2] Ding J, Wang YC. Realistic modelling of thermal and structural behaviour of unprotected concrete filled tubular columns in fire. Journal of Constructional Steel Research 2008; 64:1086-1102.

[3] Hong S, Varma AH. Analytical modeling of the standard fire behaviour of loaded CFT columns. Journal of Constructional Steel Research 2009; 65:54-69.

[4] ABAQUS. ABAQUS/Standard Version 6.6 User's Manual: Volumes I-III. Pawtucket, Rhode Island: Hibbit, Karlsson \& Sorenson, Inc.; 2005. 
[5] Lie TT, Caron SE. Fire resistance of circular hollow steel columns filled with siliceous aggregate concrete: Test results. Internal report No. 570. Ottawa, Canada: Institute for Research in Construction, National Research Council of Canada; 1988.

[6] Lie TT, Chabot M. Experimental studies on the fire resistance of hollow steel columns filled with bar-reinforced concrete. Internal report No. 628. Ottawa, Canada: Institute for Research in Construction, National Research Council of Canada; 1992.

[7] Grandjean G, Grimault JP, Petit L. Determination de la duree au feu des profiles creux remplis de beton. Convention Nº7210 SA/3/302. Resport CIDECT 15B. 1972.

[8] CEN (European Committee for Standardisation). EN 1994-1-2, Eurocode 4: Design of composite steel and concrete structures, Part 1.2: General rules - Structural fire design. Brussels: CEN; 2005.

[9] Lie TT. Fire resistance of circular steel columns filled with bar-reinforced concrete. Journal of Structural Engineering-ASCE 1994; 120(5):1489-1509.

[10] CEN (European Committee for Standardisation). EN 1992-1-2, Eurocode 2: Design of concrete structures, Part 1.2: General rules - Structural fire design. Brussels: CEN; 2004.

[11] CEN (European Committee for Standardisation). EN 1993-1-2, Eurocode 3: Design of steel structures, Part 1.2: General rules - Structural fire design. Brussels: CEN; 2005.

[12] ISO (International Standards Organization). ISO 834: Fire resistance tests, elements of building construction. Switzerland: International Standards Organisation; 1980.

[13] CEN (European Committee for Standardisation). EN 1991-1-2, Eurocode 1: Actions on structures, Part 1.2: General actions - Actions on structures exposed to fire. Brussels: CEN; 2002.

[14] EN (European Committee for Standardisation). EN 1363-1: Fire resistance tests. Part 1: General requirements. Brussels: CEN; 1999. 
Espinos A, Ibañez C, Romero ML, Hospitaler A. Comparison of a three-dimensional numerical model for fire resistance of axially loaded concrete filled steel tubular columns with Eurocode 4. Journal of Structural Fire Engineering 2011; 2(2):67-79. doi: 10.1260/2040-2317.2.2.67 
Espinos A, Ibañez C, Romero ML, Hospitaler A. Comparison of a three-dimensional numerical model for fire resistance of axially loaded concrete filled steel tubular columns with Eurocode 4. Journal of Structural Fire Engineering 2011; 2(2):67-79.
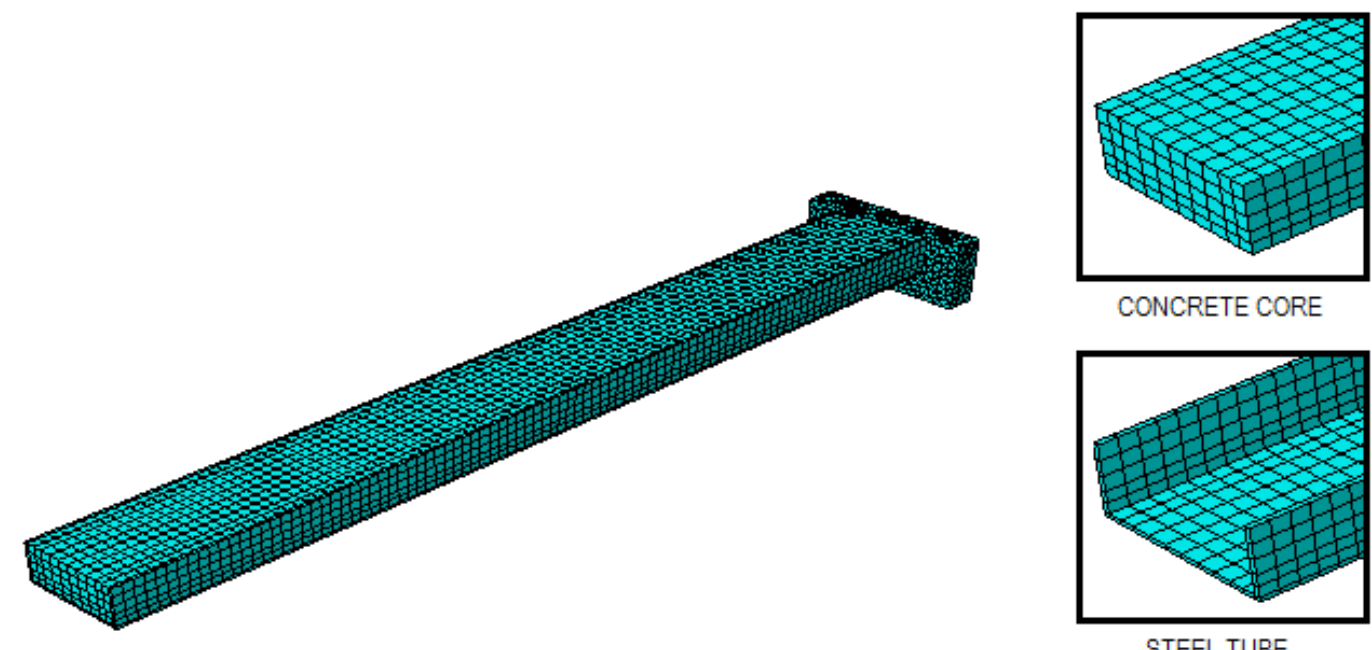

STEEL TUBE

Fig. 1. Three-dimensional finite element model for CFT columns.. 
Espinos A, Ibañez C, Romero ML, Hospitaler A. Comparison of a three-dimensional numerical model for fire resistance of axially loaded concrete filled steel tubular columns with Eurocode 4. Journal of Structural Fire Engineering 2011; 2(2):67-79.

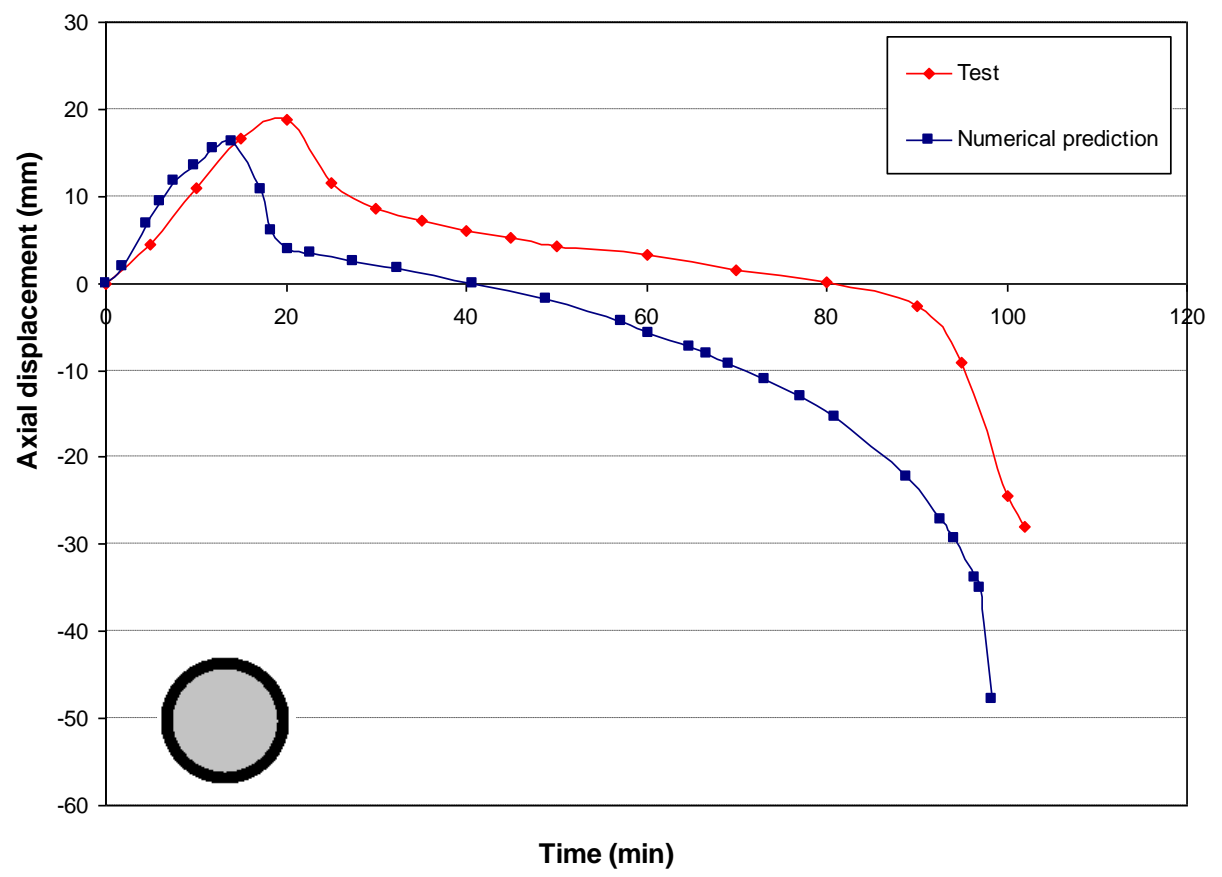

Fig. 2. Comparison between calculated and measured axial displacement, for test no. 4. 
Espinos A, Ibañez C, Romero ML, Hospitaler A. Comparison of a three-dimensional numerical model for fire resistance of axially loaded concrete filled steel tubular columns with Eurocode 4. Journal of Structural Fire Engineering 2011; 2(2):67-79.

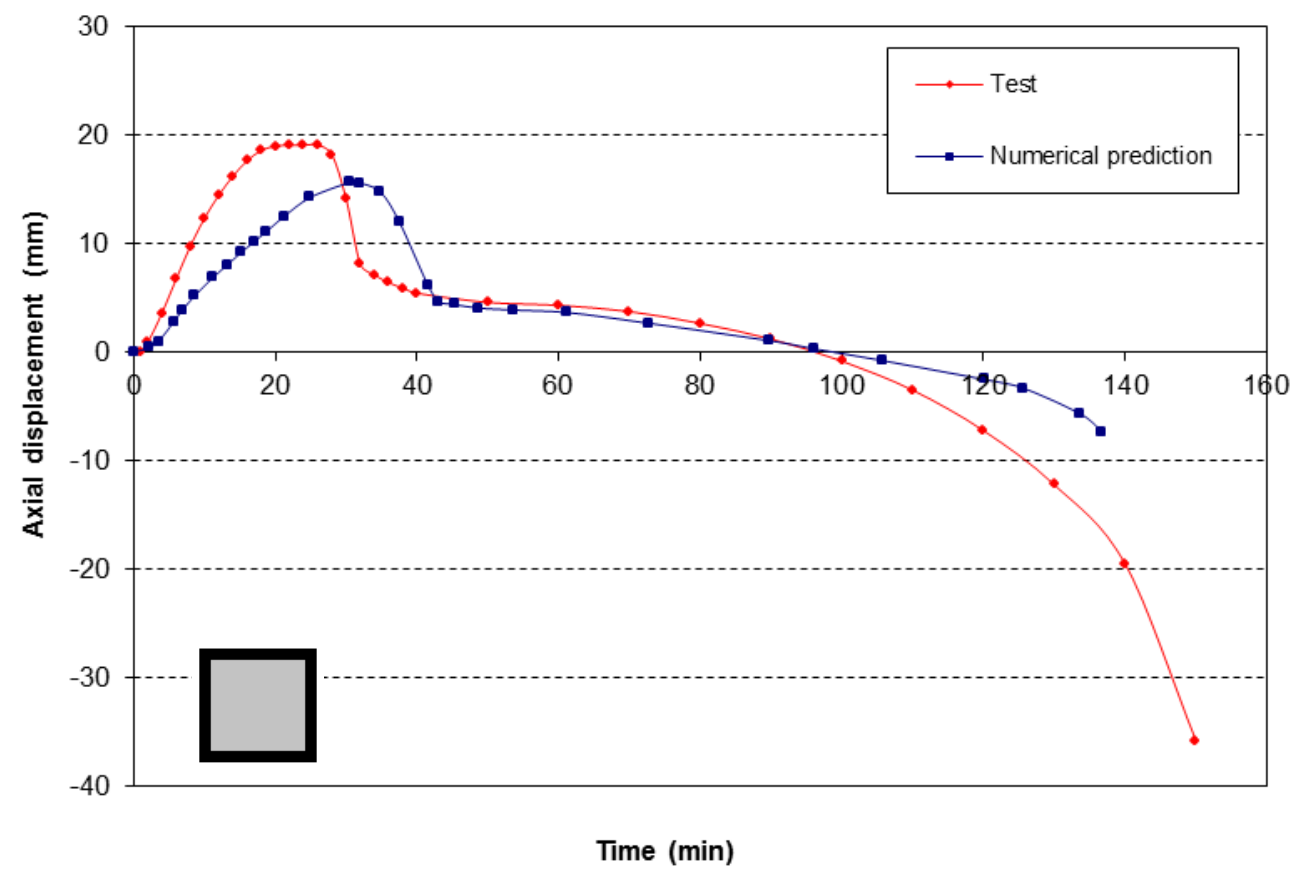

Fig. 3. Comparison between calculated and measured axial displacement, for test no. 9. 


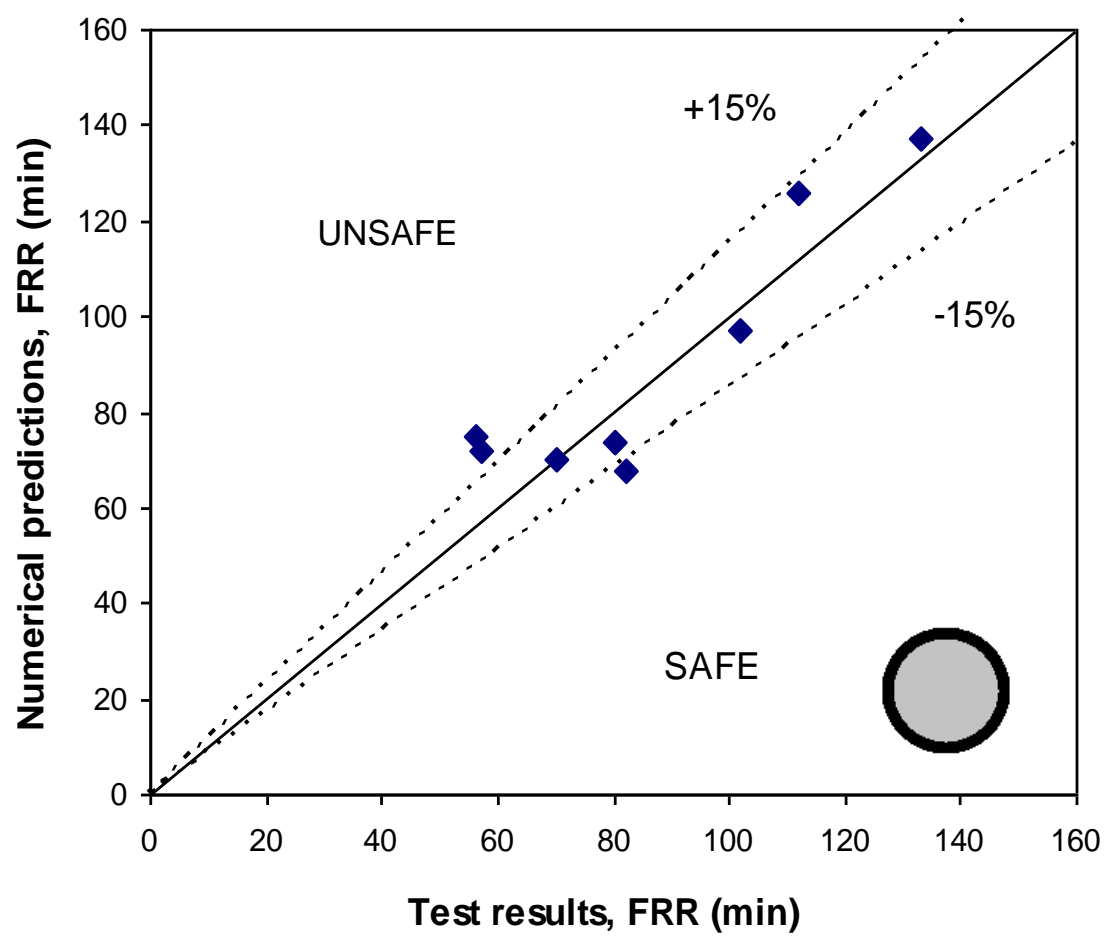

Fig. 4. Comparison of the fire resistance ratings, calculated VS test results. Circular section specimens. 


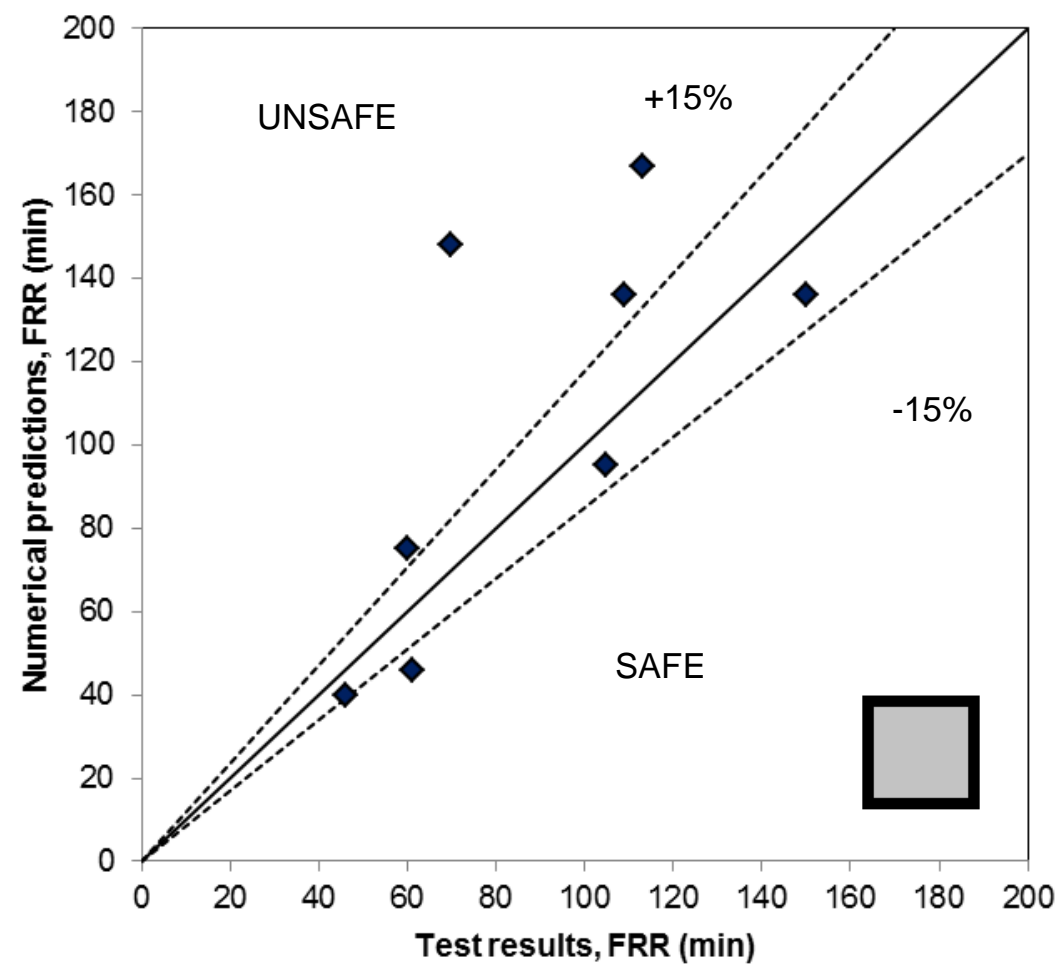

Fig. 5. Comparison of the fire resistance ratings, calculated VS test results. Square section specimens. 
Espinos A, Ibañez C, Romero ML, Hospitaler A. Comparison of a three-dimensional numerical model for fire resistance of axially loaded concrete filled steel tubular columns with Eurocode 4. Journal of Structural Fire Engineering 2011; 2(2):67-79.

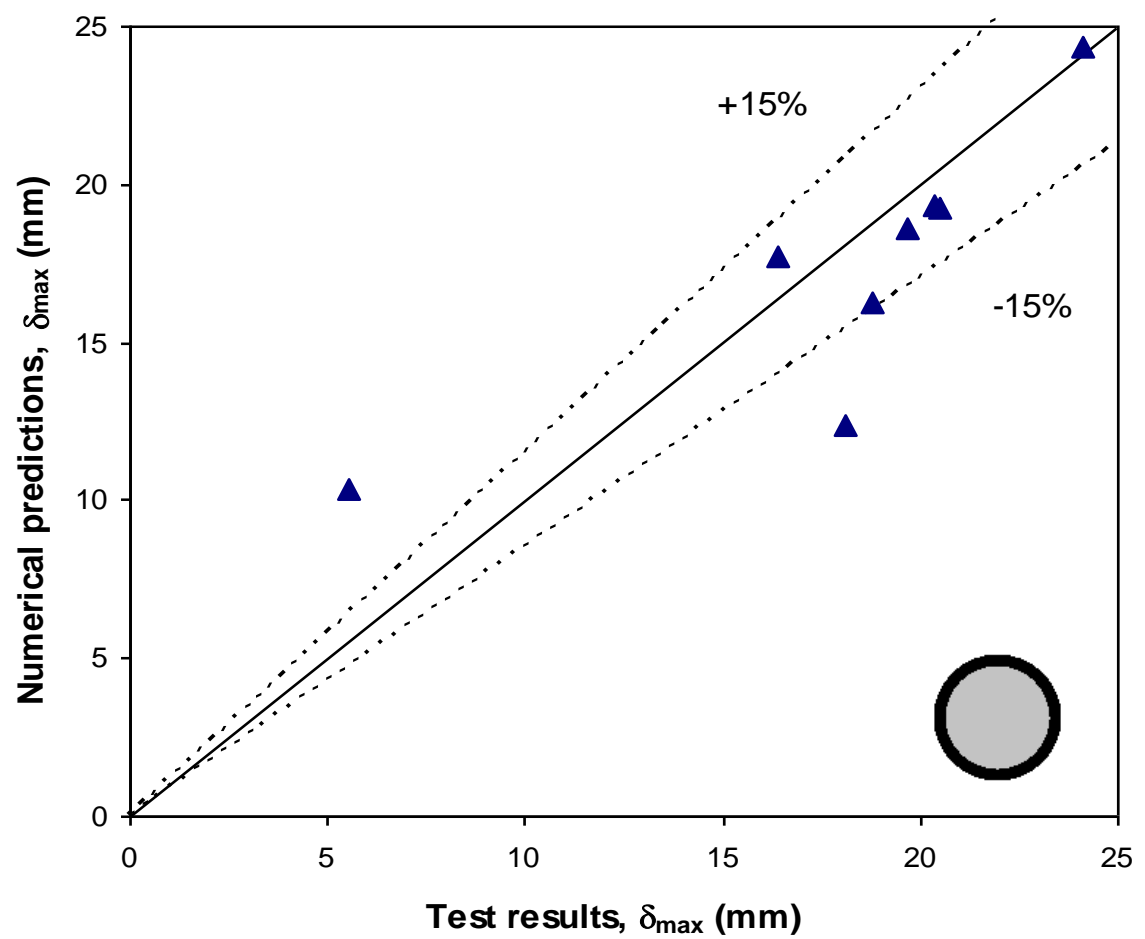

Fig. 6. Comparison of the maximum axial displacement, calculated VS test results. Circular section specimens. 


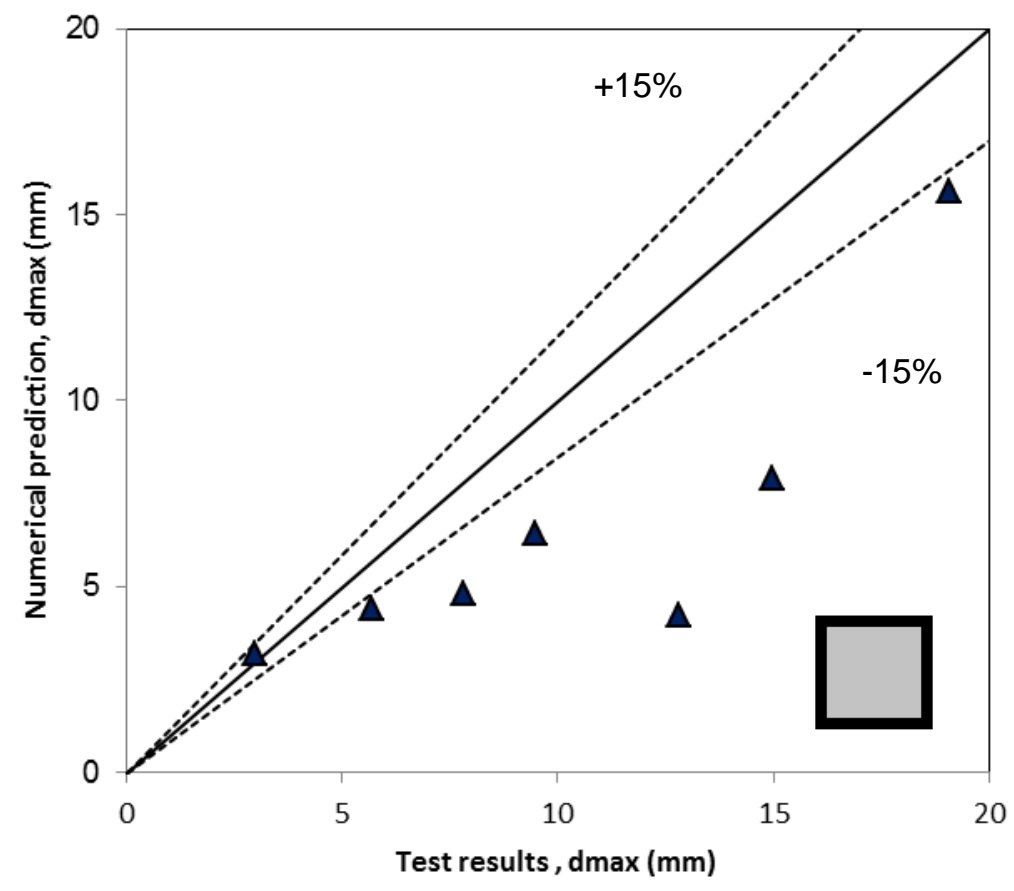

Fig. 7. Comparison of the maximum axial displacement, calculated VS test results. Square section specimens. 
Espinos A, Ibañez C, Romero ML, Hospitaler A. Comparison of a three-dimensional numerical model for fire resistance of axially loaded concrete filled steel tubular columns with Eurocode 4. Journal of Structural Fire Engineering 2011; 2(2):67-79.

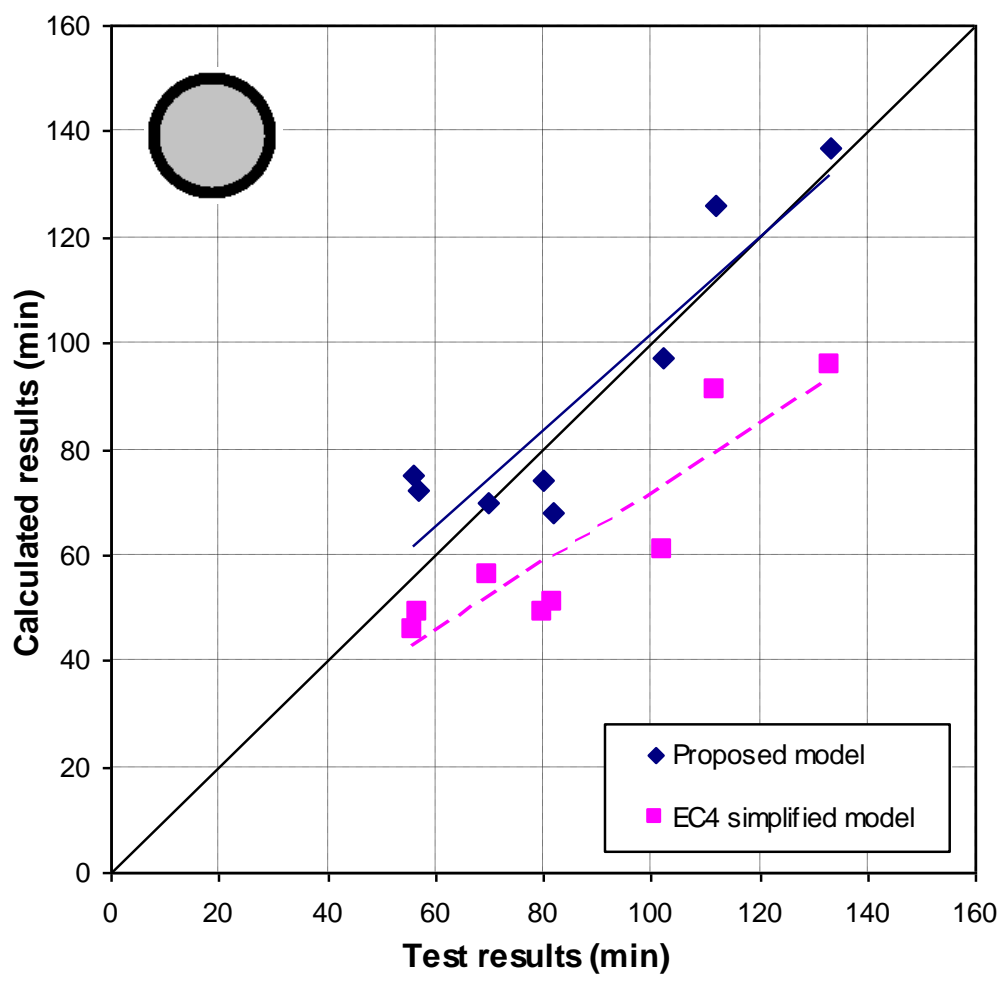

Fig. 8. Comparison of FRR, proposed numerical model VS EC4 model. Circular section specimens. 
Espinos A, Ibañez C, Romero ML, Hospitaler A. Comparison of a three-dimensional numerical model for fire resistance of axially loaded concrete filled steel tubular columns with Eurocode 4. Journal of Structural Fire Engineering 2011; 2(2):67-79.

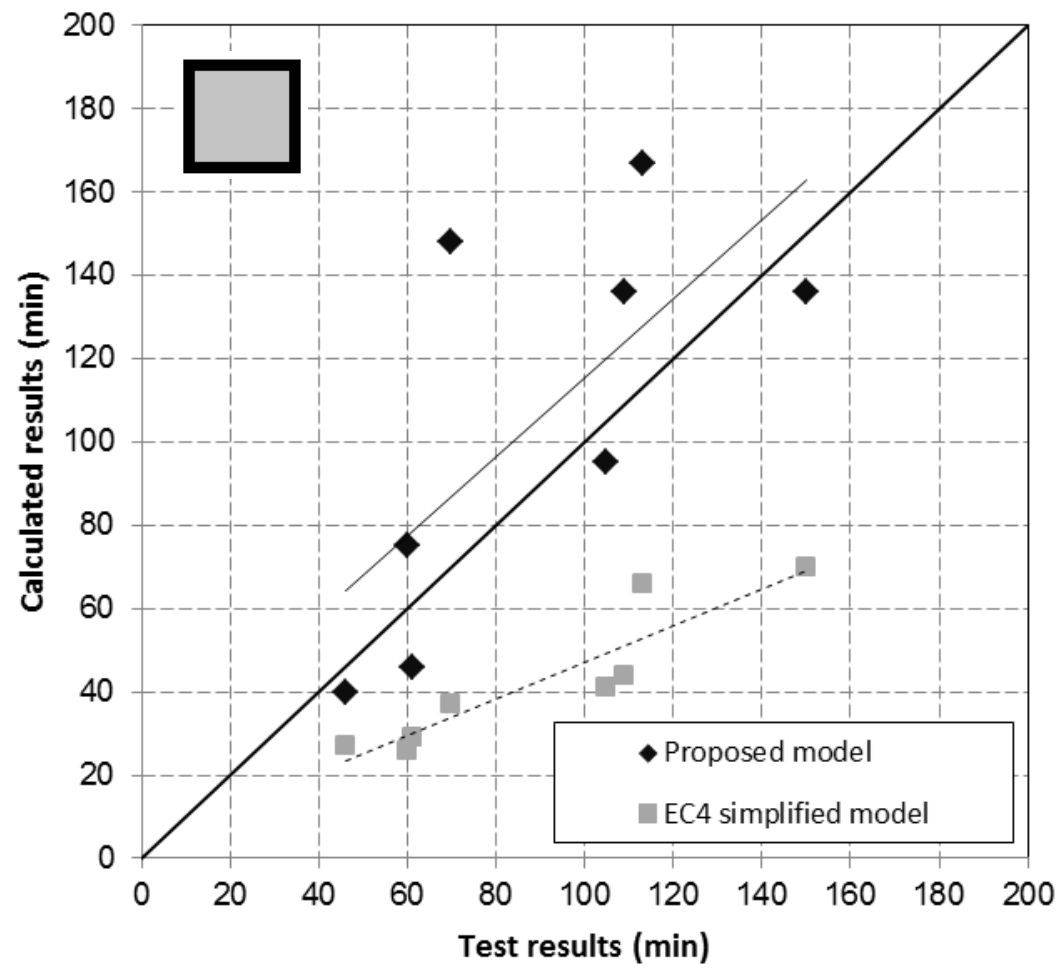

Fig. 9. Comparison of FRR, proposed numerical model VS EC4 model. Square section specimens. 
Espinos A, Ibañez C, Romero ML, Hospitaler A. Comparison of a three-dimensional numerical model for fire resistance of axially loaded concrete filled steel tubular columns with Eurocode 4. Journal of Structural Fire Engineering 2011; 2(2):67-79.

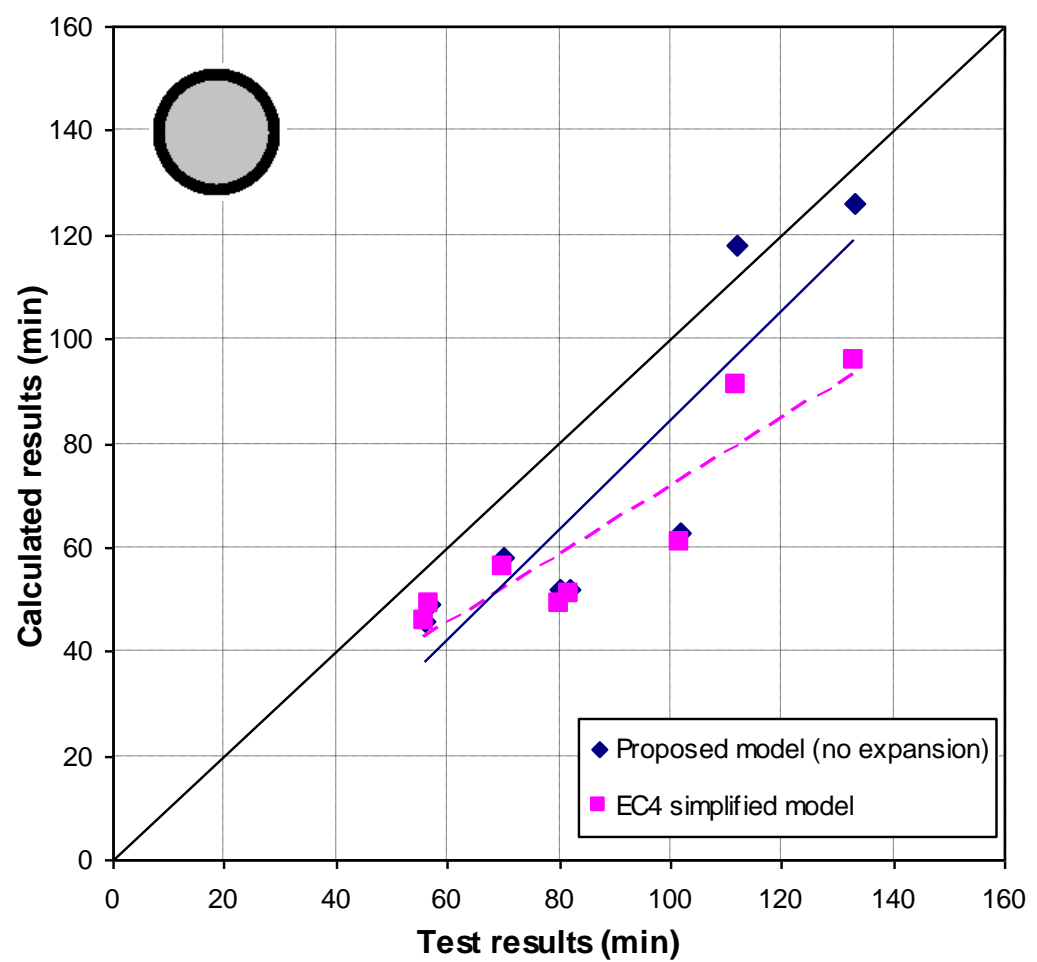

Fig. 10. Comparison of FRR, proposed model (without expansion) VS EC4 model. Circular section specimens. 

axially loaded concrete filled steel tubular columns with Eurocode 4. Journal of Structural Fire Engineering 2011; 2(2):67-79.

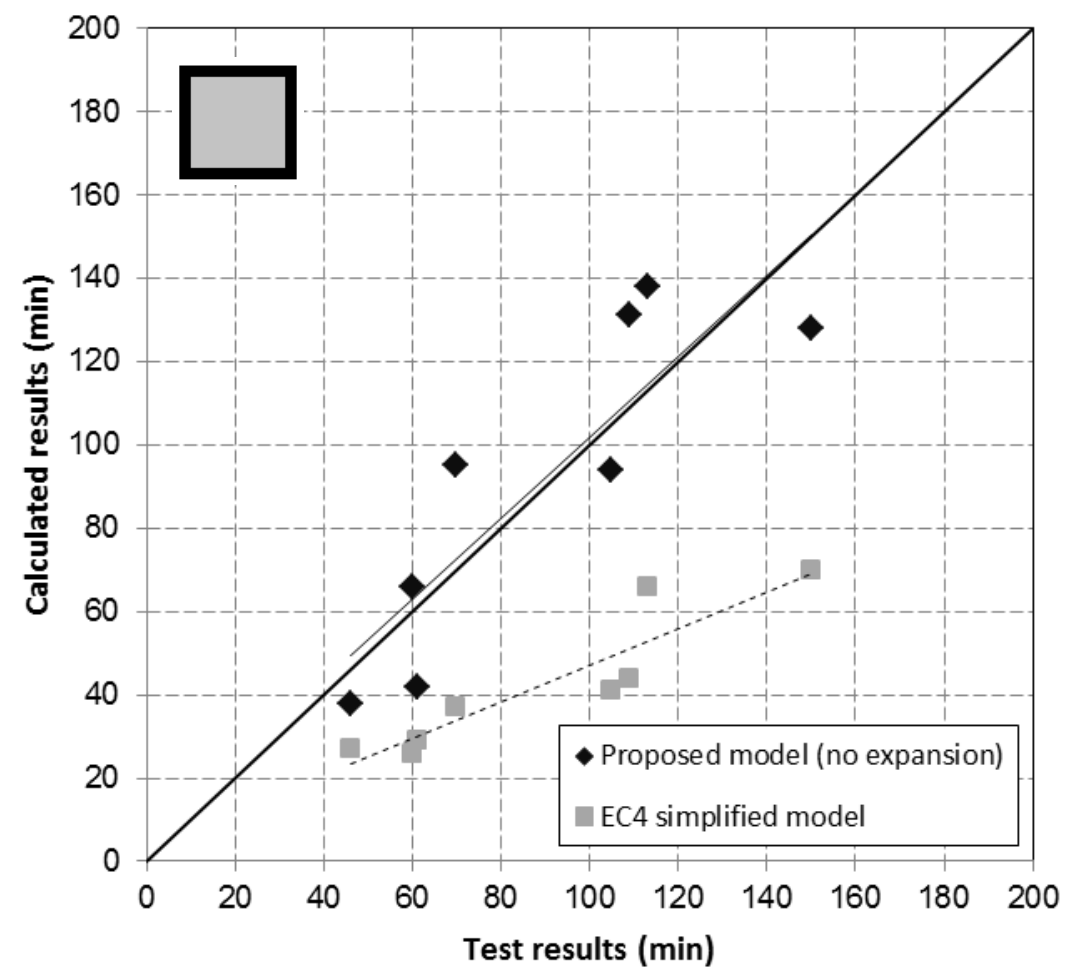

Fig. 11. Comparison of FRR, proposed model (without expansion) VS EC4 model. Square section specimens. 
Espinos A, Ibañez C, Romero ML, Hospitaler A. Comparison of a three-dimensional numerical model for fire resistance of axially loaded concrete filled steel tubular columns with Eurocode 4. Journal of Structural Fire Engineering 2011; 2(2):67-79.

Table 1. List of circular section CFT columns analyzed from the NRCC research report [5]

\begin{tabular}{|c|c|c|c|c|c|c|c|}
\hline $\begin{array}{c}\text { Column } \\
\text { specimen }\end{array}$ & $\mathbf{D}(\mathbf{m m})$ & $\mathbf{t}(\mathbf{m m})$ & $\begin{array}{c}\mathbf{f}_{\mathbf{y}} \\
\left(\mathbf{N} / \mathbf{m m}^{2}\right)\end{array}$ & $\mathbf{f}_{\mathbf{c k}}\left(\mathbf{N} / \mathbf{m m}^{\mathbf{2}}\right)$ & $\begin{array}{c}\mathbf{N} \\
(\mathbf{k N})\end{array}$ & $\boldsymbol{\mu}=\mathbf{N} / \mathbf{N}_{\mathbf{p l}, \mathbf{R d}}$ & $\begin{array}{c}\mathbf{F R R} \\
(\mathbf{m i n})\end{array}$ \\
\hline 1 & 141 & 6.5 & 401.93 & 28.62 & 131 & $8.90 \%$ & 57 \\
\hline 2 & 168 & 4.8 & 346.98 & 28.62 & 218 & $15.37 \%$ & 56 \\
\hline 3 & 219 & 4.8 & 322.06 & 24.34 & 492 & $26.19 \%$ & 80 \\
\hline 4 & 219 & 4.8 & 322.06 & 24.34 & 384 & $20.44 \%$ & 102 \\
\hline 5 & 219 & 8.2 & 367.43 & 24.34 & 525 & $18.88 \%$ & 82 \\
\hline 6 & 273 & 5.6 & 412.79 & 26.34 & 574 & $17.08 \%$ & 112 \\
\hline 7 & 273 & 5.6 & 412.79 & 26.34 & 525 & $15.63 \%$ & 133 \\
\hline 8 & 273 & 5.6 & 412.79 & 26.34 & 1000 & $29.76 \%$ & 70 \\
\hline
\end{tabular}


Table 2. List of square section CFT columns analyzed from the NRCC research report [6] and the CIDECT [7].

\begin{tabular}{|c|c|c|c|c|c|c|c|c|c|c|}
\hline $\begin{array}{c}\text { Column } \\
\text { specimen }\end{array}$ & $\begin{array}{c}\mathbf{D} \\
(\mathbf{m m})\end{array}$ & $\begin{array}{c}\mathbf{t} \\
(\mathbf{m m})\end{array}$ & Reinforcement & $\begin{array}{c}\mathbf{f}_{\mathbf{s}} \\
\left(\mathbf{N} / \mathbf{m m}^{\mathbf{2}}\right)\end{array}$ & $\begin{array}{c}\mathbf{f}_{\mathbf{y}} \\
\left(\mathbf{N} / \mathbf{m m}^{\mathbf{2}}\right)\end{array}$ & $\begin{array}{c}\mathbf{f}_{\mathbf{c k}} \\
\left(\mathbf{N} / \mathbf{m m}^{\mathbf{2}}\right)\end{array}$ & $\begin{array}{c}\mathbf{N} \\
(\mathbf{k N})\end{array}$ & $\boldsymbol{\mu}=\mathbf{N} / \mathbf{N}_{\mathbf{p l . R d}}$ & $\begin{array}{c}\text { FRR } \\
(\mathbf{m i n})\end{array}$ & ORIGIN \\
\hline 9 & 203.2 & 6.35 & $4 \phi 16$ & 350 & 400 & 37.8 & 500 & $13.26 \%$ & 150 & NRCC \\
\hline 10 & 203.2 & 6.35 & $4 \phi 16$ & 350 & 400 & 47 & 930 & $24.67 \%$ & 105 & NRCC \\
\hline 11 & 254 & 6.35 & $4 \phi 19.5$ & 350 & 400 & 48.1 & 1440 & $26.28 \%$ & 113 & NRCC \\
\hline 12 & 254 & 6.35 & $4 \phi 19.5$ & 350 & 400 & 47 & 2200 & $40.15 \%$ & 70 & NRCC \\
\hline 13 & 140 & 3.6 & $4 \phi 8$ & 388 & 388 & 41.258 & 410 & $26.06 \%$ & 46 & CIDECT \\
\hline 14 & 160 & 3.6 & $4 \phi 10+4 \phi 8$ & 380 & 380 & 35.28 & 540 & $28.62 \%$ & 61 & CIDECT \\
\hline 15 & 225 & 3.6 & $4 \phi 10+4 \phi 12$ & 355 & 355 & 35.966 & 1550 & $49.28 \%$ & 60 & CIDECT \\
\hline 16 & 260 & 6.3 & $4 \phi 14+4 \phi 14$ & 370 & 370 & 32.34 & 1500 & $32.91 \%$ & 109 & CIDECT \\
\hline
\end{tabular}


Espinos A, Ibañez C, Romero ML, Hospitaler A. Comparison of a three-dimensional numerical model for fire resistance of axially loaded concrete filled steel tubular columns with Eurocode 4. Journal of Structural Fire Engineering 2011; 2(2):67-79.

Table 3. Predicted and measured FRR and maximum axial displacement $\left(\delta_{\max }\right)$. Circular section specimens.

\begin{tabular}{|c|c|c|c|c|c|c|}
\hline \multirow{2}{*}{$\begin{array}{c}\text { Column } \\
\text { specimen }\end{array}$} & \multicolumn{2}{|c|}{ FRR (min) } & \multirow{2}{*}{$\xi_{\mathrm{FRR}}=\frac{F R R_{\text {test }}}{F R R_{N S}}$} & \multicolumn{2}{|c|}{$\delta_{\max }(\mathbf{m m})$} & \multirow{2}{*}{$\xi \delta_{\max }=\frac{\delta_{\max , t e s t}}{\delta_{\max , N S}}$} \\
\hline & Test & Simulation & & Test & Simulation & \\
\hline 1 & 57 & 72 & 0.79 & 24.09 & 24.35 & 0.99 \\
\hline 2 & 56 & 75 & 0.75 & 20.48 & 19.25 & 1.06 \\
\hline 3 & 80 & 74 & 1.08 & 18.13 & 12.36 & 1.47 \\
\hline 4 & 102 & 97 & 1.05 & 18.77 & 16.23 & 1.16 \\
\hline 5 & 82 & 68 & 1.21 & 20.36 & 19.30 & 1.05 \\
\hline 6 & 112 & 126 & 0.89 & 16.40 & 17.71 & 0.93 \\
\hline 7 & 133 & 137 & 0.97 & 19.67 & 18.61 & 1.06 \\
\hline \multirow[t]{3}{*}{8} & 70 & 70 & 1.00 & 5.51 & 10.35 & 0.53 \\
\hline & \multicolumn{2}{|c|}{ Average } & 0.97 & \multicolumn{2}{|c|}{ Average } & 1.03 \\
\hline & \multicolumn{2}{|c|}{ Standard deviation } & 0.15 & \multicolumn{2}{|c|}{ Standard deviation } & 0.26 \\
\hline
\end{tabular}


Espinos A, Ibañez C, Romero ML, Hospitaler A. Comparison of a three-dimensional numerical model for fire resistance of axially loaded concrete filled steel tubular columns with Eurocode 4. Journal of Structural Fire Engineering 2011; 2(2):67-79.

Table 4. Predicted and measured FRR and maximum axial displacement $\left(\delta_{\max }\right)$. Square section specimens.

\begin{tabular}{|c|c|c|c|c|c|c|}
\hline \multirow{2}{*}{$\begin{array}{c}\text { Column } \\
\text { specimen }\end{array}$} & \multicolumn{2}{|c|}{ FRR (min) } & \multirow{2}{*}{$\xi_{\mathrm{FRR}}=\frac{F R R_{\text {test }}}{F R R_{N S}}$} & \multicolumn{2}{|c|}{$\delta_{\max }(\mathrm{mm})$} & \multirow{2}{*}{$\xi \delta_{\max }=\frac{\delta_{\text {max }, \text { est }}}{\delta_{\text {max }, N S}}$} \\
\hline & Test & Simulation & & Test & Simulation & \\
\hline 9 & 150 & 136 & 1.10 & 19.08 & 15.65 & 1.22 \\
\hline 10 & 105 & 95 & 1.11 & 14.98 & 7.92 & 1.89 \\
\hline 11 & 113 & 167 & 0.68 & 12.82 & 4.23 & 3.03 \\
\hline 12 & 70 & 148 & 0.47 & 2.97 & 3.18 & 0.93 \\
\hline 13 & 46 & 40 & 1.15 & 7.8 & 4.8 & 1.63 \\
\hline 14 & 61 & 46 & 1.33 & 5.7 & 4.43 & 1.29 \\
\hline 15 & 60 & 75 & 0.80 & No data & 2.29 & No data \\
\hline \multirow[t]{2}{*}{16} & 109 & 136 & 0.80 & 9.5 & 6.41 & 1.48 \\
\hline & \multicolumn{2}{|c|}{ Average } & 0.93 & \multicolumn{2}{|c|}{ Average } & 1.64 \\
\hline
\end{tabular}


Espinos A, Ibañez C, Romero ML, Hospitaler A. Comparison of a three-dimensional numerical model for fire resistance of axially loaded concrete filled steel tubular columns with Eurocode 4. Journal of Structural Fire Engineering 2011; 2(2):67-79.

Table 5. Comparison of the numerical model and EC4 predictions with the tests. Circular section specimens.

\begin{tabular}{|c|c|c|c|c|c|c|c|}
\hline \multirow{2}{*}{$\begin{array}{c}\text { Column } \\
\text { specimen }\end{array}$} & \multicolumn{5}{|c|}{ FRR (min) } & \multicolumn{3}{c|}{$\xi_{\text {FRR }}=\frac{F R R_{\text {test }}}{F R R_{\text {calc }}}$} \\
\cline { 2 - 8 } & Test & Simulation & $\begin{array}{c}\text { Simulation } \\
\text { (no expansion) }\end{array}$ & EC4 & Simulation & $\begin{array}{c}\text { Simulation } \\
\text { (no expansion) }\end{array}$ & EC4 \\
\hline 1 & 57 & 72 & 49 & 49 & 0.79 & 1.16 & 1.16 \\
\hline 2 & 56 & 75 & 46 & 46 & 0.75 & 1.22 & 1.22 \\
\hline 3 & 80 & 74 & 52 & 49 & 1.08 & 1.54 & 1.63 \\
\hline 4 & 102 & 97 & 63 & 61 & 1.05 & 1.62 & 1.67 \\
\hline 5 & 82 & 68 & 52 & 51 & 1.21 & 1.58 & 1.61 \\
\hline 6 & 112 & 126 & 118 & 91 & 0.89 & 0.95 & 1.23 \\
\hline 7 & 133 & 137 & 126 & 96 & 0.97 & 1.06 & 1.39 \\
\hline 8 & 70 & 70 & 58 & 56 & 1.00 & 1.21 & 1.25 \\
\hline & & \multicolumn{7}{|c|}{ Average } & $\mathbf{0 . 9 7}$ & $\mathbf{1 . 2 9}$ & $\mathbf{1 . 3 9}$ \\
\hline
\end{tabular}


Espinos A, Ibañez C, Romero ML, Hospitaler A. Comparison of a three-dimensional numerical model for fire resistance of axially loaded concrete filled steel tubular columns with Eurocode 4. Journal of Structural Fire Engineering 2011; 2(2):67-79.

Table 6. Comparison of the numerical model and EC4 predictions with the tests. Square section specimens.

\begin{tabular}{|c|c|c|c|c|c|c|c|}
\hline \multirow{2}{*}{$\begin{array}{l}\text { Column } \\
\text { specimen }\end{array}$} & \multicolumn{4}{|c|}{ FRR (min) } & \multicolumn{3}{|c|}{$\xi_{\text {FRR }}=\frac{F R R_{\text {test }}}{F R R_{\text {calc }}}$} \\
\hline & Test & Simulation & $\begin{array}{c}\text { Simulation } \\
\text { (no expansion) }\end{array}$ & EC4 & Simulation & $\begin{array}{c}\text { Simulation } \\
\text { (no expansion) }\end{array}$ & EC4 \\
\hline 9 & 150 & 136 & 128 & 70 & 1.10 & 1.17 & 2.14 \\
\hline 10 & 105 & 95 & 94 & 41 & 1.11 & 1.12 & 2.56 \\
\hline 11 & 113 & 167 & 138 & 66 & 0.68 & 0.82 & 1.71 \\
\hline 12 & 70 & 148 & 95 & 37 & 0.47 & 0.74 & 1.89 \\
\hline 13 & 46 & 40 & 38 & 27 & 1.15 & 1.21 & 1.70 \\
\hline 14 & 61 & 46 & 42 & 29 & 1.33 & 1.45 & 2.10 \\
\hline 15 & 60 & 75 & 66 & 26 & 0.80 & 0.91 & 2.31 \\
\hline \multirow[t]{3}{*}{16} & 109 & 136 & 131 & 44 & 0.80 & 0.83 & 2.48 \\
\hline & & & & Average & 0.93 & 1.03 & 2.11 \\
\hline & \multicolumn{4}{|c|}{$\begin{array}{r}\text { Average } \\
\text { Standard deviation }\end{array}$} & 0.29 & 0.25 & 0.33 \\
\hline
\end{tabular}




\section{LIST OF FIGURE CAPTIONS}

Fig. 1. Three-dimensional finite element model for CFT columns..

Fig. 2. Comparison between calculated and measured axial displacement, for test no. 4.

Fig. 3. Comparison between calculated and measured axial displacement, for test no. 9.

Fig. 4. Comparison of the fire resistance ratings, calculated VS test results. Circular section specimens.

Fig. 5. Comparison of the fire resistance ratings, calculated VS test results. Square section specimens.

Fig. 6. Comparison of the maximum axial displacement, calculated VS test results. Circular section specimens.

Fig. 7. Comparison of the maximum axial displacement, calculated VS test results. Square section specimens.

Fig. 8. Comparison of FRR, proposed numerical model VS EC4 model. Circular section specimens.

Fig. 9. Comparison of FRR, proposed numerical model VS EC4 model. Square section specimens.

Fig. 10. Comparison of FRR, proposed model (without expansion) VS EC4 model. Circular section specimens.

Fig. 11. Comparison of FRR, proposed model (without expansion) VS EC4 model. Square section specimens. 


\section{LIST OF TABLE CAPTIONS}

Table 1. List of circular section CFT columns analyzed from the NRCC research report [5]

Table 2. List of square section CFT columns analyzed from the NRCC research report [6] and the CIDECT [7].

Table 3. Predicted and measured FRR and maximum axial displacement $\left(\delta_{\max }\right)$. Circular section specimens.

Table 4. Predicted and measured FRR and maximum axial displacement $\left(\delta_{\max }\right)$. Square section specimens.

Table 5. Comparison of the numerical model and EC4 predictions with the tests. Circular section specimens.

Table 6. Comparison of the numerical model and EC4 predictions with the tests. Square section specimens. 